\title{
МЕТОДИКА ОСВОБОЖДЕНИЯ МЕСТА В ЗУБНОМ РЯДУ НИЖНЕЙ ЧЕЛЮСТИ ДЛЯ ПРОРЕЗЫВАНИЯ ПОСТОЯННЫХ ЗУБОВ
}

\begin{abstract}
A.
METHOD OF FREEING UP SPACE
IN THE DENTITION OF THE LOWER JAW
FOR THE ERUPTION OF PERMANENT
TEETH
A. Voskanyan
N. Nuikina
R. Topolyan
Summary. The aim - of the work is to evaluate the effectiveness of
the orthodontic device proposed by the authors, which can be used to
lengthen the dentition of both the lower and upper jaw and to free up
space for eruption of permanent teeth in case of its deficiency. Materials
and methods. The device was tested in 10 patients aged 10-12 years
with the diagnosis "mesial migration of permanent molars as a result
of early loss of temporary teeth, lack of space for eruption of permanent
premolar sand canines" on the basis of the children's dental department
of the dental polyclinic of the FSBEl HE KubSMU of the Ministry of Health
of Russia. Results. After 6 months of treatment on the device for molar
distalization, the lack of space for teeth 3.5 and 4.3 was eliminated, which
allowed us to proceed to the second stage - fixing the bracket system
to achieve the final result. Conclusion. Many disadvantages of removable
devices are minimized, since no cooperation with the patient is required,
the period of habituation is accelerated, the period of active treatment is
reduced, and the number of breakdowns and losses is reduced. And most
importantly, these devices help to shorten the period of active treatment
with the help of a bracket system.
\end{abstract}
Keywords: children, dental anomalies, molar distalization.

\author{
Верапатвелян Анжела Францевна \\ К.м.н., директор, врач-ортодонт, ООО «Вера Дент», \\ 2. Краснодар \\ Angvic@mail.ru \\ Волобуев Владимир Викторович \\ К.м.н., дочент, ФГБОУ ВО «Кубанский \\ Государственный Медицинский Университет» \\ Минздрава России, г. Краснодар \\ Vladimir.volobueff@yandex.ru \\ Восканян Армине Рафиковна \\ К.м.н., дочент, ФГБОУ ВО «Кубанский \\ Государственный Медицинский Университет» \\ Минздрава России, г. Краснодар \\ voskanyan82@mail.ru \\ Нуйкина Наталья Викторовна \\ Врач-ортодонт, ООО «Вера Дент», г. Краснодар \\ kalchohok@mail.ru \\ топольян Ануш Вартановна \\ Врач-ортодонт, ООО «Вера Дент», г. Краснодар \\ tincle@mail.ru \\ топольян Рубен Вартанович \\ Зубной техник, ООО «Вера Дент», г. Краснодар \\ id_topolyan@icloud.com
}

Аннотация. Цель работы - оценить эффективность предлагаемого авторами ортодонтического устройства, которое может быть использовано для удлинения зубного ряда, как нижней, так и верхней челюсти и освобождения места для прорезывания постоянных зубов при его дефиците. Материалы и методы. Устройство было апробировано у 10 пациентов в в03расте 10-12 лет с диагнозом «мезиальная миграция постоянных моляров в результате ранней потери временных зубов, дефицит места для прорезывания постоянных премоляров и клыков» на базе детского стоматологического отделения стоматологической поликлиники ФГБОУ ВО КубГМУ Минздрава России. Результаты. По истечении 6 месяцев лечения на аппарате для дистализации моляров дефицит места для зубов 3.5 и 4.3 был устранен, что позволило перейти ко второму этапу — фиксации брекет-системы для достижения конечного результата.

Заключение. Сводятся к минимуму многие недостатки съемных аппаратов, так как не требуется кооперации с пациентом, ускоряется период привыкания, уменьшается период активного лечения, снижается количество поломок и потерь. И самое главное - эти устройства помогают сократить период активного лечения с помощью брекет-системы.

Ключевые слова: дети, зубочелюстные аномалии, дистализация моляров. 


\section{Введение}

$\mathbf{P}$ аннее удаление временных и постоянных зубов приводит не только к снижению жевательной эффективности, но и вызывает морфологическую перестройку зубочелюстной системы за счет мезиальной миграции зубов и зачатков [1,2]. Это приводит к деформации зубных дуг и формированию аномалии окклюзии, причиной которых служит отсутствие места в зубном ряду для прорезывающихся постоянных зубов, что ведет к их смещению в сторону дефекта. Этот зуб становится препятствием на пути прорезывания следующего: таким образом формируется ретенция зубов, не позволяющая постоянным зубам прорезываться по нормальной схеме.

Литературные данные указывают, что вторичные деформации зубочелюстной области выявляются у $18,6 \%$ детей. Их причиной явились дефекты зубных рядов в результате разрушения временных зубов осложнениями кариеса $(9,1 \%)$, врожденной адентии $(2,7 \%)$ и раннего удаления временных зубов (6,8\%). Сочетание аномалий положения зубов и зубных дуг встречается у $27,2 \%$ обследованных. Наиболее часто сочетаются аномалии положения зубов, зубных дуг и окклюзии в одном и двух направлениях (34,2\% и 31,60\% соответственно). Сочетание зубочелюстных аномалий одновременно в сагиттальном, вертикальном и трансверсальном направлениях выявляются, в среднем, у 2,4\% обследованных детей [3].

При лечении таких пациентов ставится вопрос об удалении постоянных зубов (чаще первых премоляров) для создания места в зубном ряду и перемещении клыков на созданное пространство. Если на основании проведенных исследований (измерения диагностических моделей челюстей и рентгенологического исследования) делается вывод о мезиальной миграции постоянных зубов с одной или двух сторон, то возможно использование современных несъемных ортодонтических устройств для дистализации моляров $[4,5,6,7]$. Эти устройства наиболее эффективны в конечном периоде сменного и формирующегося постоянного прикуса у растущих пациентов, когда вторые постоянные моляры еще не прорезались. Однако при отсутствии зачатков третьих моляров на верхней челюсти их применение возможно и после 18 лет[8].

К устройствам для дистализации моляров верхней челюсти относятся как съемные вне- и внутриротовые, такие как лицевая дуга, пластинки с винтом и секторальным распилом, которые требуют хорошей кооперации врача и пациента, так и несъемные, среди которых аппараты «Pendulum», «First Class», «FROG» $[9,10]$. Однако для дистализации моляров на нижней челюсти указанные аппараты не приемлемы.
Це^ь

Оценить эффективность предлагаемого авторами ортодонтического устройства (дистализатора моляров нижней челюсти), которое может быть использовано для удлинения зубной дуги, как нижней, так и верхней челюсти и освобождения места для прорезывания постоянных зубов при его дефиците [11].

Материалы и методы. Устройство было апробировано у 10 пациентов в возрасте 10-12 лет с диагнозом «мезиальная миграция постоянных моляров в результате ранней потери временных зубов, дефицит места для прорезывания постоянных премоляров и клыков» на базе детского стоматологического отделения стоматологической поликлиники ФГБОУ ВО КубГМУ Минздрава России.

Ортодонтическое устройство (дистализатор моляров нижней челюсти), состоит из литых коронок на молярах и премолярах с закрепленными на них параллельными между собой трубками и балками с пружинами (рис. 1).

За счет двусторонних пружин по отношению к перемещаемому зубу создается давление, с внешней и внутренней сторон зуба, для контролируемого перемещения зуба вдоль направляющих балок, что предотвращает односторонний наклон или разворот моляра и тем самым снижает риск осложнений при перемещении зубов. Литые коронки моделируют индивидуально по форме зуба с учетом межзубных контактов, поэтому не требуется сепарация зубов при фиксации конструкции. Что облегчает его припасовку в полости рта, обеспечивает плотное прилегание к поверхности зуба, снижает количество поломок устройства, уменьшает дискомфорт пациента и упрощает изготовление конструкции.

Дистализатор не требует кооперации с пациентом, так как его активирует врач-ортодонт один раз в две недели. Активации первые две недели лечения не требуется, так как длина пружин больше расстояния между коронками зубов на 5 мм. Таким образом, пружины с первого дня лечения находятся в сжатом состоянии и перемещают зубы, что ускоряет процесс лечения. Длина балок больше расстояния между перемещаемыми зубами на величину места, которое требуется создать для прорезывания зубов.

Активация заключается в создании давления путем сжатия пружины в области припаянной балки и фиксации на балку ограничителя, например, из светоотверждаемого материала. Пружину со стороны языка можно покрыть биоинертным эластичным материалом для изоляции языка и удобства пациента. 


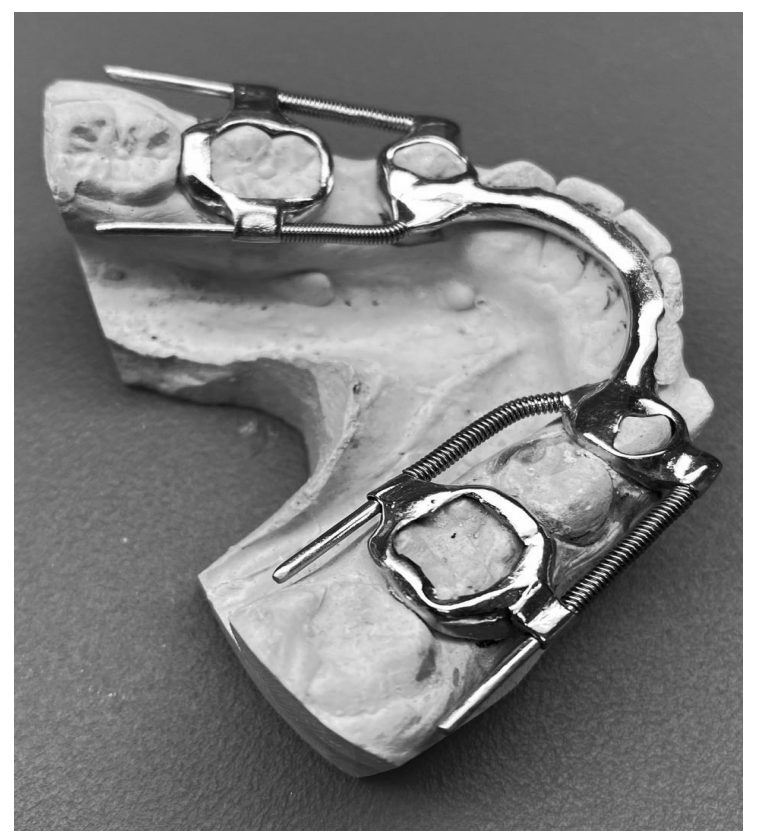

Рис. 1. Дистализатор моляров нижней челюсти на модели

\section{Результаты и обсужление}

Результат клинического использования дистализатора демонстрирует представленный клинический случай:

Пациент М., 10 лет. В результате ранней потери временных моляров (зубы 8.4 и 7.5) постоянные моляры (зубы 4.6, 3.6) прорезались ближе по зубному ряду и укоротили его, что привело к дефициту места для зубов 4.3 и 3.5 по 7 мм и 5 мм соответственно. После полноценной диагностики решено было провести лечение имеющейся патологии в два этапа. На первом этапе (подготовительном) для освобождения места в зубной дуге для прорезывания постоянных зубов 4.3 и 3.5 использовали предлагаемое ортодонтическое устройство в течение 6 месяцев, на втором - несъемную технику (брекет-система).

Ортодонтические коронки фиксировали на зубы 4.4, 4.6, 3.4,3.6. Стальные балки с надетой пружиной вставили в трубки. Язычная дуга из стали при этом опиралась на пришеечную область резцов и клыков. Конструкция сразу активная, так как длина пружин больше расстояния между коронками перемещаемых зубов. Также, как и длина стальных балок больше расстояния между перемещаемыми зубами на величину места, которое требовалось создать. Активацию проводили один раз в 2 недели, которая заключалась в создании давления на дистализируемый зуб, путем сжатия пружины в области припаянной балки и фиксации на балку ограничителя из светоотверждаемого материала. За счет активации пружин в течение пяти месяцев лечения получили удлинение зубного ряда, и создали место для прорезывания постоянных зубов.

При этом не наблюдалось осложнений в виде неконтролируемого разворота зуба по оси, за счет двухсторонних пружин по отношению к перемещаемому зубу. Стальные балки с внутренней и внешней стороны моляров создали условия для контролируемого перемещения зубов и не позволили наклоняться и развернуться молярам в другую сторону, что снизило количество осложнений при перемещении зубов, повысило эффективность ортодонтического лечения. Дуги и балки изготавливали из медицинской стали, что исключило деформацию устройства при нагрузке.

По истечении 6 месяцев лечения на аппарате для дистализации моляров дефицит места для зубов 3.5 и 4.3 был устранен (рис. 2),

что позволило перейти ко второму этапу лечения фиксации брекет-системы для достижения конечного результата (рис. 3).

\section{Зак^ючение}

Таким образом, дистализация моляров является первым этапом в лечении пациентов с аномалиями окклюзии и вестибулопозицией клыков или премоляров при мезиальной миграции боковой группы зубов. В зависимости от клинического случая возможно перемещение моляров с одной или двух сторон. Применение вышеописанного 


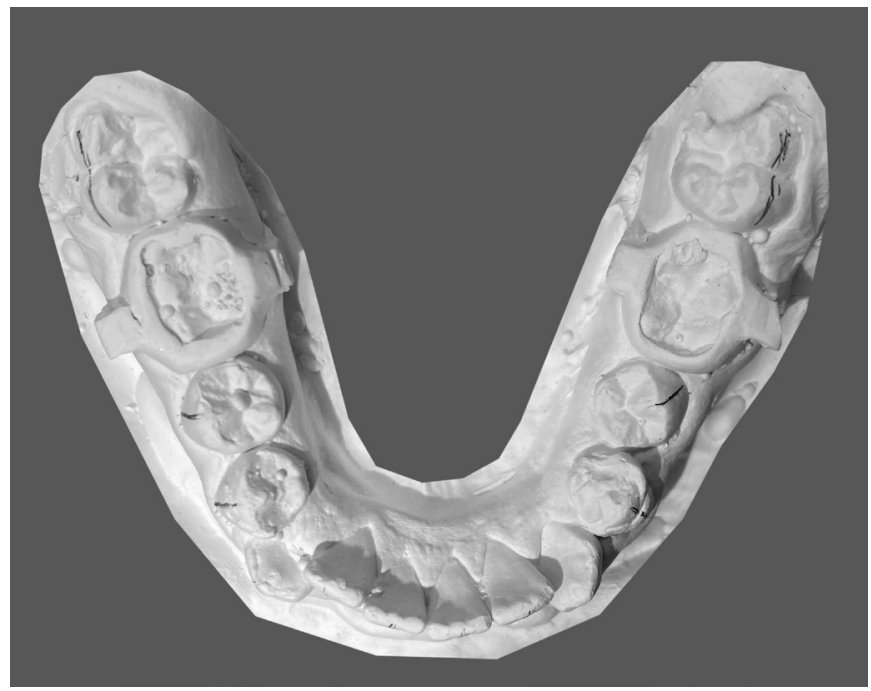

Рис. 2. Модель нижней челюсти пациента через 5 мес. после начала лечения

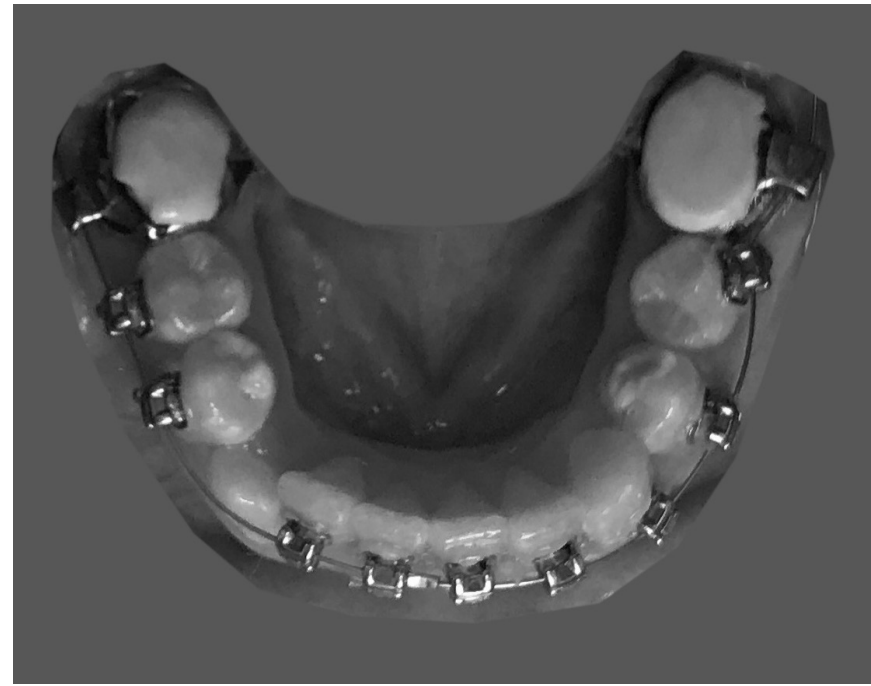

Рис. 3. Результат после 6 мес. лечения (установлена брекет-система) устройства для дистализации боковой группы зубов приводит к их корпусному перемещению и позволяет избежать удаления постоянных зубов при лечении аномалий окклюзии зубных рядов у растущих пациентов, что ведет к стабильным результатам лечения, положительно сказывается на лицевых признаках пациента, их профиле. Сво- дятся к минимуму многие недостатки съемных аппаратов, так как не требуется кооперации с пациентом, ускоряется период привыкания, уменьшается период активного лечения, снижается количество поломок и потерь. И самое главное - эти устройства помогают сократить период активного лечения с помощью брекет-системы.

\section{ЛИТЕРАТУРА}

1. Cernei E.R., Maxim D.C., Zetu I.N. The influence of premature loss of temporary upper molars on permanent molars. — Rev. Med. Chir. Soc. Med. Nat., Iaşi — 2015; 119 (1): 236-42.

2. Lin Yng-Tzer J., Lin Yai-Tin.Long-term space changes after premature loss of a primary maxillary first molar. — Journal of Dental Sciences. — 2017 ; Mar; 12 (1): 44-48. D0I: 10.1016/j.jds.2016.06.005

3. Восканян А.Р., Аюпова Ф.С., Зобенко В.Я., Алексеенко С.Н. Распространенность и характер зубочелюстных аномалий у детей, проживающих в г. Краснодар и в отдельных территориях Краснодарского края.—Вестник Волгоградского государственного медицинского университета. - 2017; 4(64): 67-71.

4. Almuzian M., Alharbi F., White J.E., Mclntyre G.T. Distalising molars — how do you do it? — Orthodontics Update. — 2016; Apr;9(2): 46-50. D0l: 10.12968/ ortu.2016.9.2.42

5. Bowman S.J. Overview Upper-Molar Distalization and the Distal Jet. — JC0. — 2016; L (3): 159-69.

6. Keles A., Sayinsu K.A new approach in maxillary molar distalization: Intraoral bodily molar distalizer — Am. J. of Orthod. and Dentofac. Orthopedics. — 2000; Vol. 117; Is.1; Jan: 39-48. D0I: 10.1016/50889-5406(00)70246-0

7. Kumar A. Molar distalization — A review. — USDJ.— 2018; 2 (2): 63-9.

8. Fontana M., Cozzani M., Caprioglio A. Soft tissue, skeletal and dentoalveolar changes following conventional anchorage molar distalization therapy in class II non growing subjects: a multicentric retrospective study // Prog Orthod._2012; May;13 (1): 30-41.

9. Björn Ludwig, Bettina Glasl, Gero S.M. Kinzinger Kevin C. Walde, Jörg A. Lisson The Skeletal Frog Appliance forMaxillary Molar Distalization // JC0. —2011; XLV (2): 77-84.

10. Sodagar A., Ahmad Akhoundi M.S., Rafighii A., Arab S. Fabrication and evaluation of a noncompliant molar distalizing appliance: bonded molar distalizer // J Dent (Tehran).-2011; Sum; 8(3): 107-116.

11. Верапатвелян А.Ф., Нуйкина Н.В., Топольян А.В., Топольян Р.В. Устройство для освобождения места в зубном ряду нижней челюсти для прорезывания постоянных зубов. - Патент на изобретение RUNo 2731796, действ. 08.09.2020 